\title{
KONTRIBUSI PENGGUNAAN INTERNET SEBAGAI SUMBER BELAJAR DENGAN HASIL BELAJAR MAHASISWA JURUSAN TEKNIK OTOMOTIF FT-UNP
}

\author{
DedyAulia $^{1}$, Martias $^{2}$, TotoSugiarto ${ }^{3}$ \\ 1,2,3 Jurusan Teknik Otomotif FT UNP, Fakultas Teknik, Universitas Negeri Padang \\ 1'dedyaulia1@gmail.com, ${ }^{2}$ martiasft@gmail.com, ${ }^{3}$ toto_130274@yahoo.com
}

\begin{abstract}
Abstrak
Penelitian ini betujuan untuk mengetahui seberapa besar kontribusi penggunaan internet sebagai sumber belajar dengan hasil belajar mahasiswa jurusan teknik otomotif FT-UNP. Populasi dalam penelitian ini adalah mahasiswa angkatan 2015 yang terdaftar aktif di Jurusan Teknik Otomotif FT-UNP berjumlah 137 mahasiswa dan sampel penelitiannya 58 mahasiswa. Dari hasil penelitian diperoleh tingkat pencapaian penggunaan internet sebagai sumber belajar (X) sebesar 92,97\% (sangat baik) dan tingkat pencapaian hasil belajar (Y) sebesar 83,95\% (baik). Adanya hubungan yang positif dan signifikan dengan koefisien korelasi $r$ hitung $>\mathrm{r}$ tabel $(0,456>0,254)$ dan uji keberartian korelasi didapat $\mathrm{t}$ hitung $>\mathrm{t}$ tabel $(4,322>2,003)$ pada taraf signifikan 5\%. Kekuatan hubungannya tergolong cukup kuat. Pengujian determinansi menunjukkan penggunaan internet memberikan signifikan terhadap hasil belajar $20 \%$.
\end{abstract}

Kata Kunci: Penggunaan Internet Sebagai Sumber Belajar, Hasil Belajar.

\begin{abstract}
This research purpose to find out how much the contribution of internet usage as a learning resource with the learning outcomes of students of automotive engineering FT-UNP. The population in this study were the 2015 class students who were enrolled actively in the Automotive Engineering Department of UNP-FT, totaling 137 students and the sample of the study was 58 students. From the results of the study, the level of achievement of internet use as a learning resource (X) is $92.97 \%$ (very good) and the level of learning achievement (Y) is $83.95 \%$ (good). The existence of a positive and significant relationship with the correlation coefficient $r$ count $>r$ table $(0.456>0.254)$ and the significance test correlation obtained $t$ count $>t$ table $(4.322>2.003)$ at a significant level of $5 \%$. The strength of the relationship is quite strong. Determination of determinants shows that internet usage provides significant learning outcomes of $20 \%$.
\end{abstract}

Keywords: Use of the Internet as a Learning Source, Learning Outcomes.

Received date 20/11/2019, Revised date 18/12/2019, Accepted date 07/01/2020 


\section{PENDAhULUAN}

Perkembangan teknologi yang pesat pada masa kini salah satunya dapat dilihat melalui perkembangan teknologi salah satunya berbasis onlien atau web. Pembelajaran setidaknya melibatkan 4 elemen yang menjadi syarat terjadi pembelajaran. Sistem Pendidikan Nasional dalam UU RI No. 20 Tahun 2003 [1] mendefinisikan mengenai pembelajaran yaitu, pembelajaran adalah proses interaksi peserta didik dengan pendidik dan sumber belajar pada suatu lingkungan belajar. Berdasarkan hal tersebut maka untuk meningkatkan kualitas pembelajaran di sekolah idealnya keempat elemen itulah yang seharusnya menjadi fokus perbaikan dan pengembangan. Oleh karena itu perlu adanya interaksi pembelajaran yang dapat melalui interaksi dengan sumber belajar.

Sumber belajar dapat berasal dari buku, jurnal ilmiah, internet, majalah, koran, televisi, dan sebagainya. Perkembangan teknologi jaringan Internet telah mengubah paradigma dalam mendapatkan informasi dan berkomunikasi, yang tidak lagi dibatasi oleh dimensi ruang dan waktu. Melalui keberadaan internet mereka bisa mendapatkan informasi yang dibutuhkan dimanapun dan kapanpun waktu yang diinginkan [2]. Pesatnya perkembangan kuantitas pengguna internet juga turut meningkatkan nilai manfaat dari internet itu sendiri. Internet sebagai sumber informasi belum dapat dimanfaatkan secara maksimal untuk mendukung pendidikan.

Internet adalah suatu jaringan komputer yang sangat besar, terdiri dari jutaan perangkat komputer yang terhubung melalui suatu protocol tertentu untuk pertukaran informasi antar komputer tersebut. Semua komputer terhubung di internet melakukan pertukaran informasi melalui protocol yang sama yaitu dengan TCP/IP (Transmission Control Protocol/Internet Protocol) [3]. Internet juga bermanfaat bagi para pengajar dalam mengembangkan profesinya, karena dengan internet dapat: (a) meningkatkan pengetahuan, (b) berbagi sumber diantara rekan sejawat, (c) bekerjasama dengan pengajar di luar negeri, (d) kesempatan mempublikasikan informasi secara langsung, (e) mengatur komunikasi secara teratur, dan (f) berpartisipasi dalam forum-forum lokal maupun internasional. Pengajar juga dapat memanfaatkan internet sebagai sumber bahan mengajar 
dengan mengakses rencana pembelajaran atau silabus online dengan metodologi baru, mengakses materi kuliah yang cocok untuk mahasiswanya, serta dapat menyampaikan ide-idenya. Internet sebagai media diharapkan akan menjadi bagian dari suatu proses belajar mengajar di perguruan tinggi karena internet mampu memberikan dukungan bagi terselenggaranya proses komunikasi interaktif antara dosen dengan mahasiswa sebagaimana yang dipersyaratkan dalam suatu kegiatan pembelajaran [4].

Sejauh ini, pendidikan di Indonesia sudah menunjukkan perkembangan yang begitu pesat. Hal ini dapat dibuktikan dengan bertambah majunya dunia tekonlogi dan pembangunan yang merupakan salah satu tujuan umum di Indonesia. Terkait dengan dunia pendidikan, tujuan lembaga pendidikan Universitas Negeri Padang untuk menyiapkan peserta didik menjadi anggota masyarakat yang memiliki kemampuan akademik dan/atau profesional yang dapat menerapkan, mengembangkan dan/atau menciptakan ilmu pengetahuan, teknologi dan/atau kesenian, mengembangkan dan menyebarluaskan ilmu pengetahuan, teknologi dan/atau kesenian, serta mengupayakan penggunaannya untuk meningkatkan taraf kehidupan masyarakat dan memperkaya kebudayaan nasional. Mahasiswa sebagai bagian dari civitas akademika ikut membantu dalam menyukseskan tujuan dari UNP tersebut. Hal itu dapat diwujudkan salah satunya dengan cara meningkatkan hasil belajar. Hasil belajar memuaskan dapat diperoleh mahasiswa dengan cara mengikuti prosedur pembelajaran yang telah disesuaikan.

Menurut [5] hasil belajar adalah tingkat keberhasilan yang dicapai oleh siswa setelah mengikuti suatu kegiatan pembelajaran dimana tingkat keberhasilan itu ditandai dengan skala nilai berupa huruf, angka dan simbol. Menurut [6] mendifinisikan bahwa "Hasil belajar adalah sebagai terjadinya perubahan tingkah laku pada diri seseorang yang dapat diamati dan diukur bentuk pengetahuan, sikap dan keterlampilan. Jadi dapat disimpulakan hasil belajar merupakan tingkat keberhasilan mahasiswa setelah mengikuti suatu pembelajaran, dimana keberhasilan ditandai dengan skala nilai, huruf dan simbol yang diperoleh/dikuasai yang merupakan hasil adanya suatu proses belajar mengajar yang berlangsung. 
Hasil belajar merupakan tolak ukur dalam menilai seseorang mahasiswa. Hasil belajar di perguruan tinggi merupakan salah satu seseorang dalam memberikan penilaian bagi mahasiswa per semester pada mata kuliah tertentu dan juga merupakan syarat mutlak untuk memasuki dunia kerja. Banyak perusahaan-perusahaan yang memasukkan IPK sebagai salah satu per syaratannya. IPK minimal 2.75 sampai 3.00 .

Ada dua faktor yang mempengaruhi hasil belajar, yaitu: (1) faktor internal, faktor yang berasal dari dalam terdiri dari faktor-faktor fisiologis seperti: intelegensi, minat, bakat, motivasi, presepsi, cara belajar dan lain-lain. (2) faktor ekternal, faktor yang berasal dari luar terdiri dari faktor-faktor sosial dan faktor non sosial seperti: keluarga, sekolah, masyarakat, dan lingkungan sekitar [7]. Menurut [8] "Menyatakan bahwa perubahan dan perkembangan yang berlaku dengan cepat, memerlukan penyediaan sumber belajar yang aktual, kaya informasi dan mudah terjangkau. Sumber belajar dari internet yang sangat kaya itu tidak akan memiliki arti apapun tanpa dikelola dengan baik [9]. Jadi dapat disimpulakan bahwav informasi yang ada di internet bisa di manfaatkan untuk berbagai keperluan dalam segala aspek kehidupan termasuk di dalamnya untuk kepentingan pendidikan atau proses pembelajaran

Berdasarkan dari uraian di atas yang berhubungan dengan penggunaan internet berbanding terbalik yang pernah saya jumpai di lapangan, kenyataannya mahasiswa hanya menggunakan internet untuk hiburan, contohnya membuka facebook, youtube dan hiburan yang bisa menghabiskan waktu mahasiswa. Hanya sedikit yang saya jumpai mahasiswa yang menggunakan internet untuk mencari website yang berhubungan dengan perkuliahan, padahal fasilitas internet yang diberikan oleh Universitas yang utama untuk mencari referensi yang berhubungan dengan perkuliahan.

Kurikulum merupakan salah satu faktor yang mempengaruhi prestasi akademik. Kurikulum sekarang sudah menampakkan kualitas yang cukup baik bagi keberhasilan pendidikan. Begitu juga dengan lingkungan mahasiswa yang umumnya berada pada lingkungan pendidikan yang baik. Dengan adanya faktor-faktor yang cukup bagus tersebut tentu akan meningkatkan hasil belajar 
mahasiswa. Namun, kenyataan yang nampak masih rendahnya hasil belajar pada mahasiswa jurusan teknik otomotif Universitas Negeri Padang.

Berdasarkan masalah-masalah yang telah penulis uraikan di atas, maka penulis tergugah untuk melaksanakan penelitian yang berjudul: "Kotribusi Penggunaan Internet Sebagai Sumber Belajar Dengan Hasil Belajar Mahasiswa Jurusan Teknik Otomotif FT-UNP”.

\section{METODA}

Penelitian ini adalah penelitian ex post facto, dimana sifat desain penelitian ini tidak memberikan perlakuan atau manipulasi, karena variabel bebas sudah terjadi. Populasi dalam penelitian ini adalah mahasiswa angkatan 2015 yang terdaftar aktif di jurusan teknik otomotif FT-UNP yang berjumlah 137 orang. Sampel penelitian yang akan dijadikan responden sebanyak 58 sampel. Instrumen pada penelitian ini menggunakan kuisioner/angket dengan skala Likert yang sudah diuji validitas dan reliabilitasnya. Data persepsi mahasiswa tentang penggunaan internet di kampus diperoleh secara langsung dari responden melalui angket yang diberikan kepadanya. Kemudian data hasil belajar diperoleh dari nilai IPK.

\section{HASIL DAN PEMBAHASAN}

Hasil belajar adalah suatu penilaian akhir dari proses dan pengenalan yang telah dilakukan berulang-ulang. Serta akan tersimpan dalam jangka waktu lama atau bahkan tidak akan hilang selama-lamanya karena hasil belajar turut serta dalam membentuk pribadi individu yang selalu ingin mencapai hasil yang lebih baik lagi sehingga akan mengubah cara berpikir serta menghasilkan perilaku kerja yang lebih baik. Penelitian ini betujuan untuk mengetahui seberapa besar kontribusi penggunaan internet sebagai sumber belajar dengan hasil belajar mahasiswa jurusan teknik otomotif FT-UNP. Dari penelitian ini didapat hasil sebagai berikut: 


\section{Penggunaan Internet}

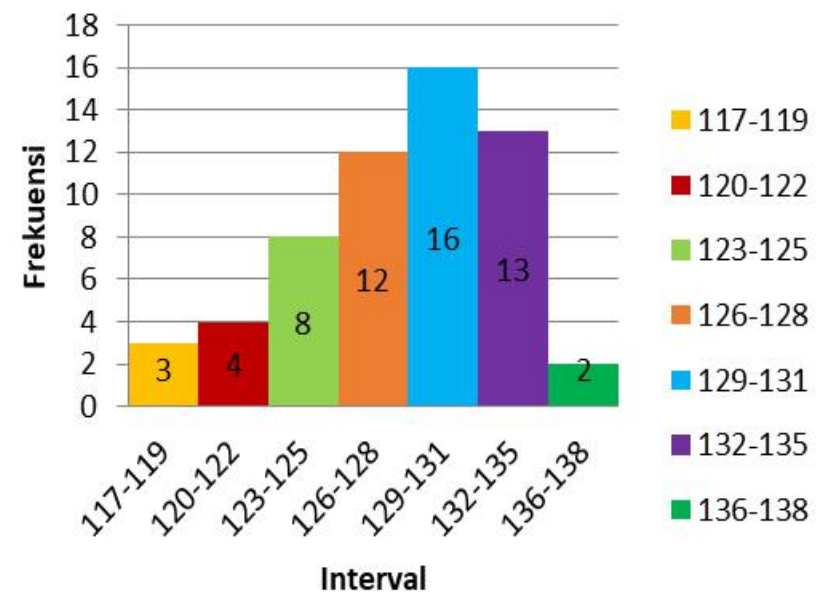

Gambar 1. Histogram Skor Penggunaan Internet

Dari pengolahan data didapat rata-rata tingkat pencapaian penggunaan internet sebagai sumber belajar sebesar 92,97\% dan masuk dalam kategori sangat baik.

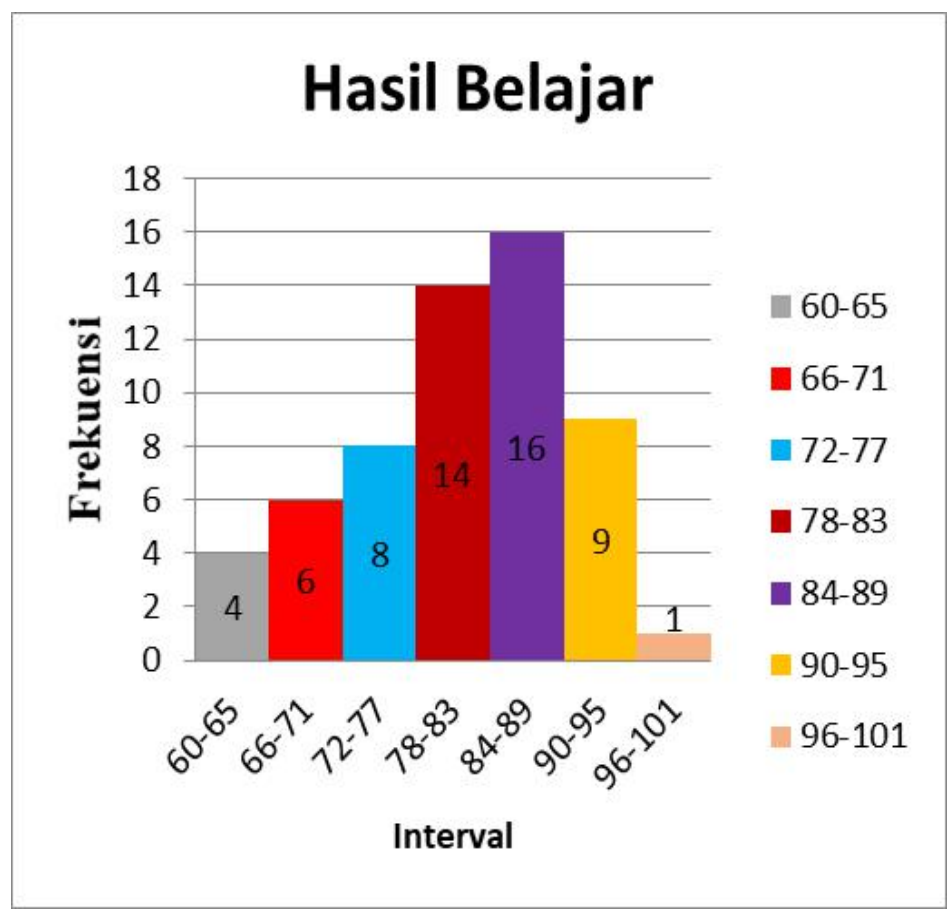

Gambar 2. Histogram Skor Hasil Belajar 
Dari pengolahan data didapat rata-rata tingkat pencapaian hasil belajar mahasiswa sebesar $83,95 \%$ dan masuk dalam kategori baik. Dari hasil penelitian tentang deskripsi data dan pengujian hipotesis menunjukan bahwa hipotesis pertama dalam penelitian ini diterima dengan didapat nilai Rxy hitung $(0,456)>r$ tabel $(0,254)$. Dengan demikian diyakini bahwa penggunaan internet sebagai sumber belajar mempunyai hubungan yang positif dan signifikan terhadap hasil belajar mahasiswa jurusan teknik otomotif FT-UNP. Selanjutnya tingkat pencapaian penggunaan internet sebagai sumber belajar sebesar 92,97\% dan tingkat pencapaian hasil belajar sebesar $83,95 \%$ dan pada pengujian keberartian korelasi didapat $\mathrm{t}$ hitung $>\mathrm{t}$ tabel $(4,322>2,003)$ dengan $\alpha=0,05$ maka terdapat hubungan yang signifikan antara penggunaan internet sebagai sumber belajar dengan hasil belajar mahasiswa. Pada uji determinasi angka $\mathrm{r}^{2}$ sebesar 0,208 atau $20 \%$.

\section{SIMPULAN DAN SARAN}

Bardasarkan hasil penelitian Pertama, tingkat pencapaian penggunaan internet sebagai sumber belajar mahasiswa jurusan teknik otomotif FT-UNP sebesar 92,97\% yang klasifikasinya tergolong sangat baik. Kedua, hasil belajar yang diperoleh mahasiswa jurusan teknik otomotif FT-UNP sebesar 83,95\% yang klasifikasinya tergolong baik. Ketiga, tingkat hubungan penggunaan internet sebagai sumber belajar dengan hasil belajar mahasiswa tergolong cukup kuat dimana koefisien korelasi $r$ hitung $(0,456)>r$ tabel $(0,254)$. Keempat, bedasarkan perhitungan thitung $(4,322)>\mathrm{t}$ tabel $(2,003)$ pada $\mathrm{N}=58, \mathrm{dk}=\mathrm{N}-2$ dan $\alpha=0,05$, maka Ho ditolak, artinya terdapat hubungan yang signifikan antara penggunaan internet sebagai sumber belajar terhadap hasil belajar mahasiswa. Dan kelima pengujian determinasi menunjukkan penggunaan internet memberikan kontribusi signifikan dengan hasil belajar sebesar $20 \%$.

Saran yang pertama ialah mahasiswa diharapkan dapat lebih memperhatikan dosen pada saat proses belajar mengajar berlangsung supaya hasil belajar mahasiswa lebih baik lagi. Kedua, mahasiswa diharapkan bisa menggunakan 
fasilitas yang diberikan pihak kampus dengan sebaik-baiknya, misalnya untuk mencari tugas kuliah atau mencari referensi.

\section{REFERENSI}

[1] Depdiknas, R. I. (2003). Departemen Pendidikan Nasional Republik Indonesia.

[2] Adri, Muhammad. (2007). Pemanfaatan Internet sebagai Sumber Pembelajaran. Makalah dalam rangka Semiloka Pengembangan Model Pembelajaran Berbasis Teknologi Informasi FT Padang, 22-23 Agustus 2007.

[3] Shahab, Alwi. (2000). Internet Bagi Profesi Kedokteran. Jakarta: EGC

[4] Setiyani, R. (2010). Pemanfaatan Internet Sebagai Sumber Belajar. Dinamika Pendidikan, 5(2).

[5] Dimiyati dan Mudjiono (2009), "Belajar dan Pembelajaran", Rineka Cipta: Jakarta

[6] Hamalik Oemar. (2001). Proses Belajar Mengajar. Jakarta: Bumi Aksara

[7] Dalyono, M. (2005). Psikologi Pendidikan. Jakarta: PT. Rineka Cipta

[8] Sadiman, Arief. S, dkk. (1993). Media Pendidikan: Pengertian, Perkembangan dan Pemanfaatannya. Jakarta : Raja Grafindo Persada

[9] Darmansyah. (2010). Pembelajaran Berbasis Web: Teori Konsep dan Aplikasi. Padang. UNP Press 